Tadbir: Jurnal Manajemen Dakwah

Volume 5, Nomor 2, 2020, 137-146

DOI: $10.15575 /$ tadbir

Fakultas Dakwah dan Komunikasi, UIN Sunan Gunung Djati Bandung https://jurnal.fdk.uinsgd.ac.id/index.php/tadbir ISSN: 2623-2014 (Print)ISSN: 2654-3648 (Online

\title{
Fundraising Dana Infak dan Sedekah dalam Meningkatkan Kepercayaan Jamaah Masjid
}

\author{
Bariek Azka Perdana ${ }^{1 *}$, Muhamad Zen ${ }^{2}$ \\ ${ }^{1}$ Program Studi Manajemen Dakwah, , Fakultas Ilmu Dakwah dan Ilmu Komunikasi, UIN Syarif \\ Hidayatullah, Jakarta \\ 2 Program Studi Manajemen Dakwah, , Fakultas Ilmu Dakwah dan Ilmu Komunikasi, UIN \\ Syarif Hidayatullah, Jakarta \\ *Email : barikarka@ymail.com \\ *Email:*zen@uinjkt.ac.id
}

\begin{abstract}
ABSTRAK
Tujuan penelitian ini adalah untuk mengetahui berbagai macam fundraising dana infak dan sedekah dalam meningkatkan kepercayaan jamaah pada LAZIS MRBJ. Penelitian ini menggunakan pendekatan penelitian kualitatif dengan teknik analisis data deskriptif. Peneliti memberikan deskripsi dari suatu temuan yang di peroleh dari LAZIS MRBJ. Teknik pengumpulan data melalui observasi di lapangan, wawancara dan dilengkapi dengan data dokumentasi. Hasil dari penelitian fundraising dana infak dan sedekah dalam meningkatkan kepercayaan jamaah pada LAZIS MRBJ yaitu bahwa LAZIS MRBJ membuat pola dalam menghimpun dana infak dan sedekah dengan berbagai program seperti kajian rutin, program anak asuh, program anak yatim, kotak harta riba serta konter infak Ramadhan dan seluruh program yang dirancang mendapat atensi serta antusias dari jamaah yang bisa dibilang cukup tinggi. Hasil perolehannya selalu mengalami peningkatan dari tahun sebelumnya. Para pengurus LAZIS MRBJ tidak cepat berpuas diri dan akan terus memperbaiki segala lini untuk menjadikan LAZIS MRBJ agar lebih baik lagi dari sebelumnya.
\end{abstract}

Kata Kunci: LAZIS MRBJ; pola; fundraising; infak; sedekah

\section{ABSTRACT}

The purpose of this research is to find out various kinds of fundraising patterns of infaq and alms in an effort to increase the trust of pilgrims at the LAZIS MRBJ. This research uses a qualitative research approach with descriptive data analysis techniques. Researchers provide a description of a finding obtained from LAZIS MRBJ. This study uses data collection techniques through observation in the field, interviews and is equipped with documentation data. The results of the research into fundraising patterns for infaq and alms funds in an effort to increase the trust of pilgrims at LAZIS MRBJ namely that LAZIS MRBJ made a 
pattern in raising infaq and alms funds with various programs such as routine studies, foster children programs, orphans programs, usury treasure boxes as well as the Ramadhan infaq counter and all programs designed to get attention and enthusiasm from pilgrims which is arguably quite high. The acquisition results always increase from the previous year. The management of LAZIS MRBJ is not fast complacent and will continue to improve all lines to make LAZIS MRBJ better than before.

Keywords: LAZIS MRBJ; patterns; fundraising; infaq; alms

\section{PENDAHULUAN}

Dalam kegiatan pengelolaan Zakat, Infak dan Sedekah di suatu lembaga pengelola ZIS, fundraising menjadi langkah awal yang harus dilalui karena organisasi pengelola Zakat, Infak dan Sedekah dalam aktifitasnya selalu berhubungan dengan dana. Fundraising merupakan kegiatan penting dan utama dalam sebuah lembaga pengelola Zakat, Infak dan Sedekah. Fundraising dapat diartikan sebagai kegiatan dalam rangka menghimpun dana ataupun sumber daya lainnya yang berasal dari masyarakat baik itu individu maupun organisasi yang digunakan untuk membiayai program dan kegiatan operasional organisasi atau lembaga sehingga tercapainya suatu tujuan (Hasanudin, 2010). Pengaruh fundraising sangat besar bagi eksistensi sebuah lembaga pengelola ZIS, karena dana ZIS dapat meningkatkan kesejahteraan masyarakat untuk membantu mengentaskan kemiskinan yang ada di negeri ini.

Potensi dan dorongan untuk terbiasa dalam berzakat, berinfak, dan bersedekah di jalan Allah SWT saya rasa telah mengakar kuat dalam kehidupan sehari-hari sebagian besar masyarakat Indonesia. Jika dana zakat saja sangat berpotensi, bagaimana dengan dana keagamaan lainnya, seperti dana infak dan sedekah yang jelas tidak ada batasan maupun syarat tertentu dalam mengeluarkan dan menyalurkannya. Karena menurut saya, potensi Infak dan Sedekah di Indonesia cukup besar dan sangat sayang bila tidak diperhatikan dan dikelola dengan baik serta bijaksana. Dana infak dan sedekah juga dapat membantu perekonomian Indonesia dalam kemandirian umat Islam jika dikelola dengan baik dan benar. Karena seperti yang kita ketahui, lembaga zakat di Indonesia tidak hanya mengelola dana zakat saja, tetapi juga dana infak dan sedekah.

Besar kecilnya dana Infak dan Sedekah yang bisa dihimpun tentu bergantung dari kepercayaan para pemberi infak dan sedekah pada lembaga tersebut. Tumbuh tidaknya kepercayaan pemberi infak dan sedekah terhadap lembaga tersebut tentu bergantung pada bagus atau tidaknya kinerja serta sesuai

atau tidaknya penyaluran dana Infak dan Sedekah terhadap para mustahik itu dengan yang disyariatkan oleh Islam.

Pola fundraising dana Infak dan Sedekah yang baik akan menciptakan kepercayaan jamaah sehingga jamaah akan terdorong untuk menyalurkan dana Infak dan Sedekah pada LAZIS Masjid Raya Bintaro Jaya. Pengelolaan dana 
Infak dan Sedekah di LAZIS Masjid Raya Bintaro Jaya, menurut saya sudah cukup transparan, sehingga membuat para jamaah percaya dengan kinerjanya yang jujur. Seperti halnya di bulan Agustus, total pendapatan dari berbagai jenis infak dan sedekah kurang lebih mencapai 285.000.000 rupiah. Hal ini juga menjadi tujuan penulis untuk mengetahui bagaimana cara LAZIS Masjid Raya Bintaro Jaya menjaga serta meningkatkan kepercayaan jamaah dan mengelola dana ZIS dengan baik dan benar.

\section{LANDASAN TEORITIS}

\section{Pola Fundraising}

Menurut Kamus Besar Bahasa Indonesia, Pola merupakan bentuk atau model yang dipakai untuk membuat dan menghasilkan sesuatu. Menurut bahasa, fundraising adalah penghimpunan dana, sedangkan menurut istilah, fundraising adalah suatu kegiatan penghimpunan dana maupun sumber daya lainnya dari masyarakat baik itu individu maupun organisasi yang akan digunakan untuk membiayai program serta kegiatan operasional lembaga untuk mencapai suatu tujuan (Hasanudin, 2010).

Dalam melakukan kegiatan fundraising, banyak pola yang dapat dilakukan. Adapun yang dimaksud pola fundraising di sini adalah suatu bentuk kegiatan yang khas yang dilakukan oleh suatu lembaga dalam rangka mengimpun dana dari masyarakat. Selain itu, fundraising juga memiliki manfaat, metode serta dasar hukum yang terdapat dalam Undang-Undang Republik Indonesia.

\section{Pengertian Infak}

Infak adalah salah satu ibadah yang bisa kita lakukan untuk menyempurnakan amalan. Selain menjalankan ibadah puasa di Bulan Ramadhan, menunaikan ibadah seperti infak, sedekah ataupun zakat juga menjadi salah satu hal yang bisa kita lakukan. Infak merupakan pengeluaran sukarela yang dilakukan seseorang setiap kali ia memperoleh rezeki sebanyak yang ia kehendakinya. Allah memberikan kebebasan untuk menentukan jenis harta maupun berapa jumlah yang sebaiknya diserahkan (Muhammad Zen, 2010).

Infak berasal dari kata anfaqa yang berarti mengeluarkan sesuatu (harta) untuk kepentingan sesuatu. Secara terminologi syariat infak berarti mengeluarkan sebagian dari harta atau pendapatan ataupun penghasilan untuk suatu kepentingan yang diperintahkan Islam (Forum Silaturrahim ZIS, 2017). Infak berbeda dengan zakat, infak tidak mengenal nisab atau jumlah harta yang telah ditentukan secara hukum. Infak juga tidak harus diberikan kepada mustahik tertentu, melainkan dapat diberikan kepada siapapun seperti keluarga, kerabat, anak yatim, atau bahkan orang miskin sekalipun.

Berdasarkan pengertian di atas, menurut saya, infak berarti menyalurkan ataupun mengeluarkan rezeki berupa harta benda yang di dapatkan secara halal 
dan atas dasar ikhlas karena Allah SWT. Karena dengan kita berinfak tidak akan menyebabkan kita miskin dan melarat, namun justru dapat mengembangkan harta kita.

\section{Pengertian Sedekah}

Kata sedekah berasal dari Bahasa Arab, yaitu "shodaqa" yang secara Bahasa berarti "benar" atau "jujur". Di sini, tersirat makna bahwa orang yang bersedekah telah menjalankan agama dengan benar atau jujur. Dengan kata lain, sedekah menjadi bukti pembenar bagi keimanan seorang muslim.

Sedangkan secara istilah, sedekah berarti sebuah pemberian secara suka rela, baik berupa uang, barang, jasa, kebaikan dan lainnya kepada orang yang berhak menerimanya dengan jumlah yang tidak ditentukan atau sekehendak dirinya dan diberikan kapan saja dan di mana saja demi mengharap ridha dan pahala dari Allah SWT (Arif Masykur, 2014). Sedekah ialah segala bentuk nilai kebajikan yang tak terikat oleh jumlah, waktu dan tak terbatas pada materi saja tetapi juga non-materi, seperti menyingkirkan batu dijalan, menuntun orang buta serta memberikan senyuman manis kepada saudaranya (Muhammad Zen, 2010).

Jika disimpulkan, menurut saya sedekah yaitu pemberian kepada orang yang membutuhkan dengan ikhlas baik itu dari segi materi seperti uang dan barang, maupun non materi seperti jasa, ilmu dan lain sebagainya.

\section{Pengertian Kepercayaan}

Kepercayaan (trust atau belief) merupakan keyakinan bahwa tindakan orang lain atau suatu kelompok konsisten dengan kepercayaan mereka. Kepercayaan lahir dari suatu proses secara perlahan kemudian terakumulasi menjadi suatu bentuk kepercayaan, dengan kata lain kepercayaan adalah keyakinan kita bahwa di satu produk ada atribut tertentu. Keyakinan ini muncul dari persepsi yang berulang adanya pembelajaran dan pengalaman (M. Taufiq Amir, 2005).

Kepercayaan adalah kekuatan bahwa suatu produk memiliki atribut tertentu. Kepercayaan itu sering disebut perkaitan objek-atribut (object-attribute linkage), yaitu kepercayaan konsumen tentang kemungkinan adanya hubungan antara sebuah objek dengan atributnya yang relevan. Sementara definisi Kepercayaan Konsumen yaitu semua pengetahuan yang dimiliki oleh konsumen, dan semua kesimpulan yang dibuat oleh konsumen tentang objek, atribut, dan manfaatnya (Etta Mamang, 2013). 


\section{Pengertian Jamaah}

Dilansir dari Wikipedia, secara bahasa, jamaah berasal dari bahasa arab yang memiliki arti, berkumpul. Misalnya jamaah pasar berarti perkumpulan orang yang ada di pasar. Jamaah menurut istilah dapat diartikan sebagai pelaksanaan ibadah secara bersama-sama yang dipimpin oleh seorang imam. Misalnya jamaah salat, jamaah haji dan lain-lain.

Dari penjelasan di atas, penulis menyimpulkan bahwa jamaah merupakan perkumpulann orang banyak yang melakukan suatu kegiatan secara bersamasama. Seperti contoh, jamaah masjid, jamaah kajian dan lain sebagainya.

\section{HASIL DAN PEMBAHASAN}

\section{Analisis Pola Fundraising Dana Infak dan Sedekah dalam Upaya Meningkatkan Kepercayaan Jamaah}

LAZIS Masjid Raya Bintaro Jaya menanamkan nilai-nilai positif bagi para amil dan pengurus agar mampu memberikan penjelasan serta pemahaman kepada masyarakat sekitar Masjid Raya Bintaro Jaya, dengan tujuan masyarakat yang belum paham tentang keutamaan atau fadhilah dari berinfak dan bersedekah serta memberikan sugesti dan pemikiran kepada para amil dan pengurus agar amanah dalam mengemban tugasnya dan mampu mewujudkan sebuah kepercayaan dari jamaah dan transparan dalam mengelola dana infak dan sedekah (Wawancara Pribadi, 2020).

LAZIS Masjid Raya Bintaro Jaya memiliki tujuan sebagai sebuah wadah yang berorientasi pada penghimpunan serta pendayagunaan dana infak dan sedekah. Tujuan ini menjadi sebuah awal dari LAZIS Masjid Raya Bintaro Jaya dalam melakukan sebuah kegiatan. Langkah awal sebelum melakukan kegiatan adalah menganalisa sehingga terbentuk suatu pola, dengan adanya pola yang digunakan menjadi sebuah gambaran dalam bentuk tahapan- tahapan fundraising yang akan dilakukan oleh LAZIS Masjid Raya Bintaro Jaya.

Dalam penyusunannya, LAZIS Masjid Raya Bintaro Jaya membuat pola dalam mengumpulkan dana infak dan sedekah, yaitu dengan berbagai program. Pertama, Kajian Rutin yang diadakan setiap hari yaitu membahas seputar apapun yang ada di dalam agama Islam meliputi tafsir, fikih, kitab, persoalan zakat, infak, dan sedekah, sejarah peradaban Islam dan masih banyak lagi beberapa persoalan lain yang ada di dalam agama Islam. Kajian Rutin ini pun terbagi lagi dalam beberapa waktu seperti kajian Ba'da Subuh, Ba'da Maghrib dan Kajian Sabtu Siang. Kedua, Program Anak Asuh, yaitu sebuah program pemberian beasiswa berupa bantuan uang sekolah untuk anak yatim maupun dhuafa yang tinggal di sekitar Masjid Raya Bintaro Jaya. Ketiga, Program Anak Yatim, yaitu dengan memberikan santunan hanya kepada anak yatim ataupun yatim piatu yang tempat tinggalnya berada di sekitar Masjid Raya Bintaro Jaya berupa uang yang diharapkan dapat dipergunakan dengan bijak untuk membantu meringankan beban hidup mereka, dengan kriteria maksimal berusia 17 tahun. 
Keempat, Kotak Harta Riba, yaitu sejumlah harta yang diperoleh dari bunga bank yang dimana Harta Riba ini tidak boleh dimanfaatkan bagi dirinya sendiri maupun keluarganya, karena Harta Riba bukanlah harta miliknya, tetapi harus dikeluarkan ataupun disedekahkan. Kelima, Konter Infak Ramadhan, berdonasi ZIS di LAZIS Masjid Raya Bintaro Jaya kini semakin mudah karena tujuan dari Konter Infak Ramadhan ini adalah memberikan kemudahan bagi Jamaah dalam menyalurkan donasinya baik itu Zakat, Infak maupun Sedekah. LAZIS Masjid Raya Bintaro Jaya telah membuka beberapa gerai penerimaan ZIS diberbagai tempat strategis seperti mall dan ini hanya berlangsung saat Bulan Ramadhan saja.

\section{Analisis Hasil Fundraising Dana Infak dan Sedekah dalam Upaya Meningkatkan Kepercayaan Jamaah}

Tahap ini merupakan sebuah tahapan selanjutnya setelah pola dirumuskan pada tahap yang sebelumnya. Disini saya mencoba menjabarkan hasil dari suatu pola yang telah dirancang oleh LAZIS Masjid Raya Bintaro Jaya dengan beberapa programnya. Pertama, Kajian Rutin. Kajian Rutin ini merupakan suatu program yang intensitasnya paling sering diantara program-program lainnya karena di adakan setiap hari. Namun, jamaah yang hadir pada Kajian Ba'da Subuh dan Kajian Ba'da Maghrib pada hari Senin-Jumat lebih sedikit dibandingkan dengan hari Sabtu dan Ahad, karena hampir sebagian dari Jamaah Masjid Raya Bintaro Jaya bekerja sebagai pegawai yang dimana hari Senin-Jumat merupakan hari kerja bagi mereka. Sebaliknya, hari Sabtu dan Ahad merupakan hari libur bagi mereka. Alasan mendasar ini pun juga berpengaruh di Kajian Sabtu Siang. Jadi, aktivitas merekapun menentukan rutinitasnya juga untuk hadir dalam kajian tersebut.

Kedua, Program Anak Asuh. Pada kenyataannya, ternyata masih banyak anak-anak yang kurang mampu yang bertempat tinggal di sekitaran Masjid Raya Bintaro Jaya yang kesulitan melanjutkan pendidikannya karena terbentur biaya. Namun, masalah tersebut sedikit terbantu dengan diadakannya Program Anak Asuh ini. Banyak dari Jamaah Masjid Raya Bintaro Jaya yang tertarik dan ikut membantu berinfak dalam program ini. Dengan adanya Program Anak Asuh ini, besar harapan Jamaah, banyak lahir generasi penerus bangsa yang merupakan ujung tombak kemajuan dan pembangunan bangsa dan negeri ini. Ketiga, Program Anak Yatim. Program ini merupakan program yang paling familiar di telinga Jamaah, yang dimana tanpa publikasi yang berlebih pun, Jamaah dengan sendirinya akan datang untuk berinfak dalam rangka membantu menyukseskan santunan untuk anak yatim ataupun yatim piatu ini, karena sebagian besar Jamaah sudah tahu betapa mulianya menyantuni anak yatim dan yatim piatu. Keempat, Kotak Harta Riba. Tidak disangka, program ini menjadi salah satu program yang paling banyak menarik minat Jamaah. Salah satu alasannya, mungkin karena Kotak Infak Harta Riba ini jarang ditemui diluar sana, karena belum banyak juga masjid lain yang menerapkan program ini, sehingga Jamaah 
juga bingung ingin menginfakkan harta riba mereka kemana, terutama Jamaah yang bertempat tinggal di sekitar Bintaro. Kelima, Konter Infak Ramadhan. Program yang hanya ada di Bulan Ramadhan ini juga tidak kalah menariknya dengan program yang lainnya. Ternyata, antusiasme Jamaah dengan Program Konter Infak Ramadhan ini cukup baik, karena Jamaah benar-benar merasakan kemudahannya dalam berinfak dan bersedekah. Seperti yang dibahas sebelumnya, LAZIS MRBJ telah mebuka gerai penerimaan ZIS di beberapa tempat strategis seperti Bintaro Plaza dan Bintaro Jaya Xchange Mall. Jadi, Jamaah dapat berinfak dan bersedekah tanpa perlu datang langsung ke Masjid Raya Bintaro Jaya.

Saat ini pengetahuan serta kesadaran Jamaah tentang infak dan sedekah terus bertambah yang dimana berpengaruh juga pada meningkatnya kepercayaan Jamaah kepada LAZIS Masjid Raya Bintaro Jaya, sehingga Jamaah percaya menyalurkan infak dan sedekahnya dibandingkan dengan lembaga-lembaga lain. Tidak hanya itu, kesadaran Jamaah tentang infak dan sedekah yang terus bertambah juga berdampak pada meningkatnya penerimaan dana infak dan sedekah di LAZIS Masjid Raya Bintaro Jaya dalam dua tahun terakhir, yaitu mulai dari tahun 2018 sampai tahun 2019 seperti pada diagram berikut ini.

Diagram 1. Grafik Perolehan Dana Infak Umum LAZIS Masjid Raya Bintaro Jaya Tahun 2018 dan 2019

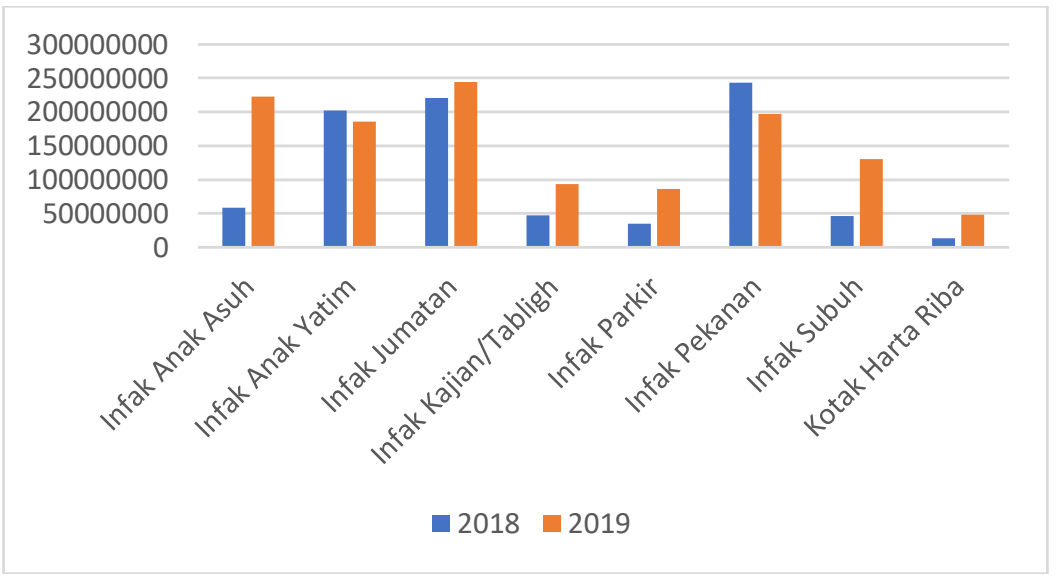

Diagram 2. Grafik Total Perolehan Dana Infak Umum LAZIS

Masjid Raya Bintaro Jaya Tahun 2018 dan 2019 


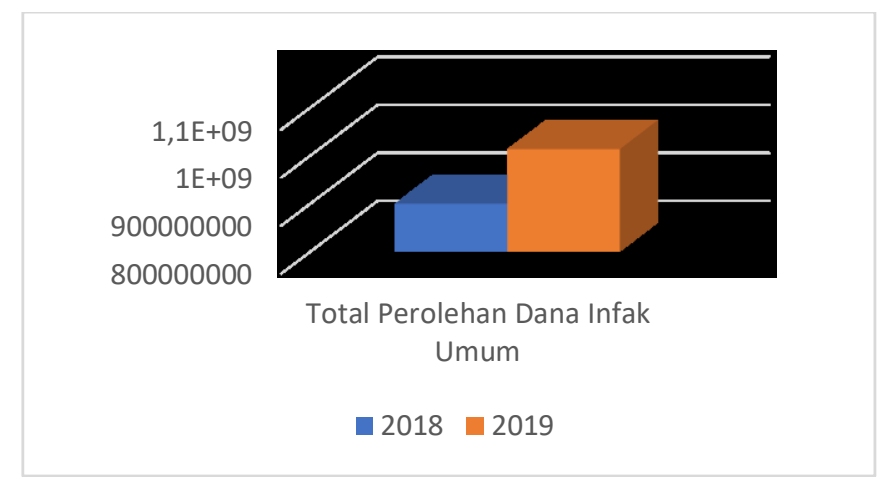

Pada grafik pertama, dijelaskan secara rinci perolehan berbagai jenis Infak Umum yang ada pada LAZIS Masjid Raya Bintaro Jaya. Walaupun ada beberapa jenis infak yang tidak mengalami perolehan peningkatan dari tahun yang sebelumnya, namun secara keseluruhan total perolehan dana Infak Umum di LAZIS Masjid Raya Bintaro Jaya mengalami peningkatan yang cukup signifikan dibandingkan dengan tahun yang sebelumnya seperti yang tertera pada grafik yang kedua.

Diagram 3. Grafik Perolehan Dana Infak dan Sedekah Ramadhan LAZIS

Masjid Raya Bintaro Jaya Tahun 2018 dan 2019

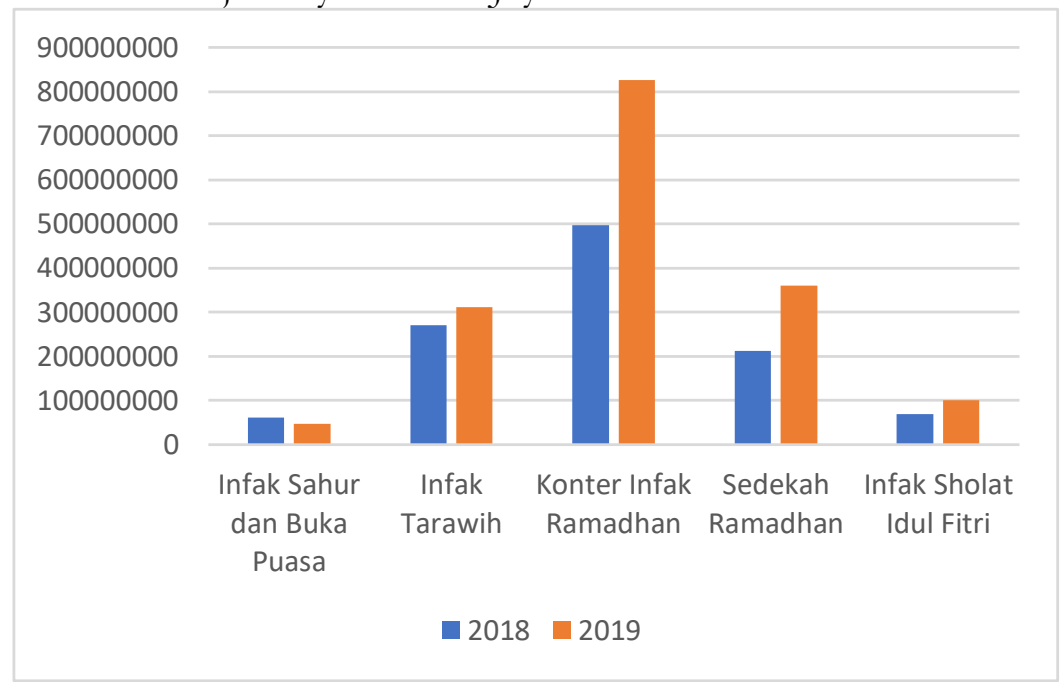

Diagram 4. Grafik Total Perolehan Dana Infak dan Sedekah Ramadhan LAZIS MRBJ Tahun 2018 dan 2019 


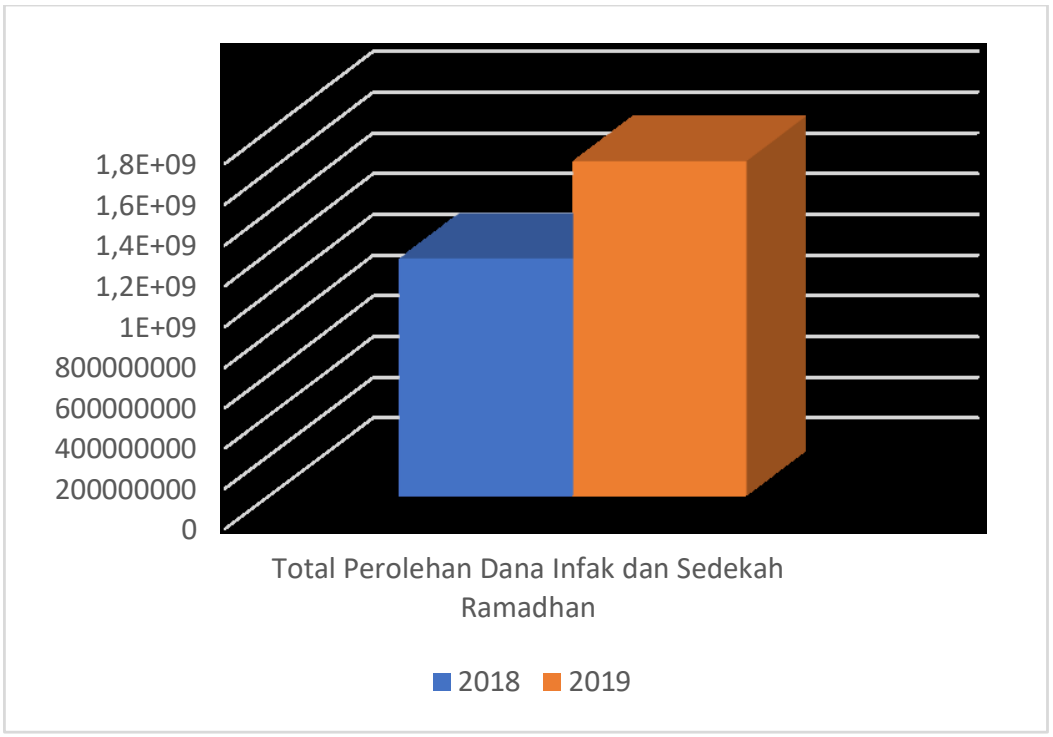

Seperti halnya pada Infak Umum, total perolehan dana Infak dan Sedekah Ramadhan di LAZIS Masjid Raya Bintaro Jaya pun juga mengalami peningkatan yang signifikan dari tahun yang sebelumnya seperti yang kita lihat pada grafik yang kedua. Hal ini membuktikan bahwa kepercayaan Jamaah yang semakin hari semakin meningkat, sehingga Jamaah percaya untuk berinfak dan bersedekah pada LAZIS Masjid Raya Bintaro Jaya.

Walaupun secara keseluruhan mengalami peningkatan, namun Pengurus LAZIS Masjid Raya Bintaro Jaya tidak boleh puas sampai situ saja, mereka akan terus menerus berbenah dalam segala hal dengan cara menciptakan inovasi, ide maupun gagasan baru serta dengan cara memperluas syiar manfaat dan keutamaan berinfak dan bersedekah serta lebih aktif lagi dalam penggunaan media sosial untuk selalu menjadikan LAZIS Masjid Raya Bintaro Jaya lebih baik lagi dikemudian hari.

\section{PENUTUP}

Berdasarkan hasil penelitian dan pembahasan mengenai pola fundraising dana infak dan sedekah dalam upaya meningkatkan kepercayaan jamaah pada LAZIS Masjid Raya Bintaro Jaya, dapat diambil kesimpulan bahwa suatu lembaga pengelola ZIS dituntut untuk aktif, kreatif, dan inovatif dalam merencanakan bentuk fundraising, dengan tujuan untuk menjaga eksistensi dari lembaga tersebut agar bertahan serta berlangsung lama. LAZIS Masjid Raya Bintaro Jaya membuat pola dalam mengumpulkan dana infak dan sedekah, yaitu dengan berbagai program seperti Kajian Rutin setiap harinya yang terbagi dalam beberapa waktu, Program Anak Asuh dengan memberikan bantuan berupa uang sekolah, Program Anak Yatim dengan memberikan bantuan berupa uang untuk 
membantu kehidupan sehari-hari, Kotak Harta Riba untuk Jamaah yang ingin berinfak dari harta yang diperoleh dari hasil bunga bank, serta Konter Infak Ramadhan untuk memudahkan Jamaah dalam berinfak dan bersedekah di tempat-tempat strategis seperti di mall dan sebagainya.

Dalam pengaplikasiannya, jika ditotal secara keseluruhan, semua program yang dirancang oleh LAZIS Masjid Raya Bintaro Jaya mendapatkan atensi serta antusias dari Jamaah yang bisa dibilang cukup tinggi, seperti pada program Kajian Rutin, Anak Asuh, Kotak Harta Riba serta Konter Infak Ramadhan, serta pada tahap akhir ini, hasil perolehan dana infak dan sedekah dari seluruh program yang dibuat oleh LAZIS Masjid Raya Bintaro Jaya bisa dibilang cukup mengejutkan yang selalu mengalami peningkatan dari tahun sebelumnya.

Akan tetapi, para pengurus LAZIS Masjid Raya Bintaro Jaya tidak cepat berpuas diri dan akan terus memperbaiki segala lini seperti dari segi syiar, inovasi, ide maupun gagasan, serta penggunaan sosial media yang lebih aktif lagi untuk menjadikan LAZIS Masjid Raya Bintaro Jaya agar lebih baik lagi dari sebelumnya.

Ada beberapa saran-saran yang ingin diberikan penulis terkait hasil penelitian ini kepada LAZIS Masjid Raya Bintaro Jaya. Tentunya saran ini bertujuan untuk menjadikan LAZIS Masjid Raya Bintaro Jaya lebih baik lagi. Walaupun hasil perolehan serta kepercayaan Jamaah yang mengalami peningkatan, namun fundraising yang dilakukan oleh LAZIS Masjid Raya Bintaro Jaya harus lebih ditingkatkan lagi agar mereka mampu mencapai target secara lebih optimal dan LAZIS Masjid Raya Bintaro Jaya juga harus terus memberikan pelayanan yang terbaik kepada Jamaah dan selalu berinovasi dalam membuat program, ide serta gagasan. Berdasarkan pembahasan di atas, maka penulis memberi beberapa saran yaitu, menambah jumlah pengurus agar kinerja lebih maksimal dan menghindari peran ganda, menggalakkan lagi dalam hal sosialisai dan manfaat serta keutamaan berinfak dan bersedekah agar kesadaran jamaah untuk berinfak dan bersedekah terus bertambah serta terus tingkatkan pelayanan bagi jamaah.

\section{DAFTAR PUSTAKA}

Amir, M. T. (2005). Dinamika Pemasaran. Jakarta: PT Raja Grafindo Persada. Arif, M. (2014) Sedekah Itu Ajib. Jogjakarta: DIVA Press.

Dabsyatnya Potensi Ziswaf di Indonesia. (2019, Desember 6). Diambil dari Rumah Zakat: $\quad$ https://www.rumahzakat.org/dahsyatnya-potensi-ziswaf-diindonesia/

Doa, M. D. J. (2004). Pengelolaan Zakat Oleh Negara Untuk Memerangi Kemiskinan. Jakarta: KORPUS.

Forum Silaturrahim ZIS. (2017). Buku Panduan Pengelolaan ZIS. Sukabumi: Forum ZIS. 
Fundraising dalam Penghimpunan Harta Wakaf. (2019, November 1). Diambil kembali dari Badan Wakaf Indonesia: bttps:// bwi.or.id/index.php/in/publikasi/artikel/394-manajemen- fundraisingdalam-penghimpunan-barta-wakaf-bagian-1.btml

Hasanudin.(2010). Manajemen Zakat dan Wakaf. Tangerang Selatan: Buku Ajar.

Infak dan Sedekah Apa Bedanya. (2019, Desember 31). Diambil kembali dari Liputan6: https://www.liputan6.com/ramadan/read/2963476/infak-dansedekah-apa-bedanya

Jamaah. (2019, November 1). Diambil kembali dari Wikipedia: https://id.wikipedia.org/wiki/Jamaah

Kementrian Agama.(2009). Manajemen Pengelolaan Zakat. Jakarta: Direktorat Pemberdayaan Zakat, Direktorat Jenderal Bimbingan Masyarakat Islam Departemen Agama Republik Indonesia.

Nata, A. (1999) Mengenal Hukum Zakat dan Infak Sedekah. Jakarta: Badan Amil Zakat Infak Sedekah DKI Jakarta.

Pengertian Jamaah. (2019, November 1). Diambil kembali dari Ahlu Tsughur: http:/ /ahlu-tsughur.blogspot.com/2017/09/pengertian-jamaah.html

Pengertian Pola. (2020, Mei 14). Diambil kembali dari https://www.kbbi.web.id/pola

Sangadji, Etta Mamang. Perilaku Konsumen, Pendekatan Peraktis. Yogyakarta: ANDI OFFSET, 2013.

Sani, M. A. (2010). Jurus Menghimpun Fulus Manajemen Zakat Berbasis Masjid. Jakarta: PT Gramedia Pustaka Utama.

Subhana, M. (2001). Dasar-dasar Penelitian Ilmiah. Bandung: CV. Pustaka Setia. . Dasar-dasar Penelitian Ilmiah. Bandung: CV Pustaka Setia, 2005.

Sudewo, E. (2004). Manajemen Zakat: Tinggalkan 15 Tradisi Terapkan 4 Prinsip Dasar. Jakarta: Institut Manajemen Zakat.

Suharsimi, A. (2006) Prosedur Penelitian Suatu Pendekatan Praktik. Jakarta: PT Renika Cipta.

Sutisna, H. (2006). Fundraising Database: Panduan Praktis Menyusun Fundraising Database dengan Microsoft Access. Depok: Piramedia.

Umar, H. (2008).Strategic Management in Action. Jakarta: PT Gramedia Pustaka Utama.

Wibowo. (2006). Manajemen Perubahan. Jakarta: PT Grafindo Persada.

Zen, M.(2010). 24 Hours of Contemporary Zakat: Tanya Jawab Seputar Keseharian Zakat. Jakarta: ZIS Indosat. 